\title{
C-terminal processing of yeast Spt7 occurs in the absence of functional SAGA complex
}

\author{
Stephen MT Hoke ${ }^{\dagger 1}$, Gaoyang Liang ${ }^{\dagger 1,2}$, A Irina Mutiu ${ }^{1}$, Julie Genereaux ${ }^{1}$ and \\ Christopher J Brandl*1
}

\begin{abstract}
Address: ${ }^{1}$ Department of Biochemistry, Schulich School of Medicine \& Dentistry, University of Western Ontario, London, N6A5C1, Canada and 2Department of Biochemistry and Biophysics, University of North Carolina at Chapel Hill, 27599-7295, USA
\end{abstract}

Email: Stephen MT Hoke - shoke@uwo.ca; Gaoyang Liang - gaoyang_liang@med.unc.edu; A Irina Mutiu - abulboac@uwo.ca; Julie Genereaux - jgenerea@uwo.ca; Christopher J Brandl* - cbrandl@uwo.ca

* Corresponding author †Equal contributors

Published: 8 August 2007

BMC Biochemistry 2007, 8:16 doi:10.1186/147|-209/-8-16
Received: 18 january 2007

Accepted: 8 August 2007

This article is available from: http://www.biomedcentral.com/I47I-209//8/16

(C) 2007 Hoke et al

This is an Open Access article distributed under the terms of the Creative Commons Attribution License (http://creativecommons.org/licenses/by/2.0), which permits unrestricted use, distribution, and reproduction in any medium, provided the original work is properly cited.

\begin{abstract}
Background: Spt7 is an integral component of the multi-subunit SAGA complex that is required for the expression of $\sim 10 \%$ of yeast genes. Two forms of Spt7 have been identified, the second of which is truncated at its C-terminus and found in the SAGA-like (SLIK) complex.

Results: We have found that C-terminal processing of Spt7 to its SLIK form (Spt7 $7_{\text {SLIK }}$ ) and to a

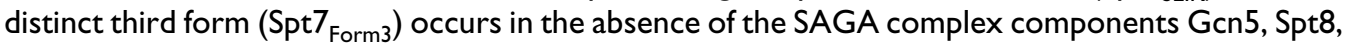
Adal and Spt20, the latter two of which are required for the integrity of the complex. In addition, $\mathrm{N}$-terminally truncated derivatives of Spt7, including a derivative lacking the histone fold, are processed, indicating that the $\mathrm{C}$-terminus of $\mathrm{Spt7}$ is sufficient for processing and that processing does not require functional Spt7. Using galactose inducible Spt7 expression, we show that the three forms of Spt7 appear and disappear at approximately the same rate with full-length Spt7 not being chased into $\mathrm{Spt}_{\mathrm{SLIK}}$ or $\mathrm{Spt}_{\mathrm{Form} 3}$. Interestingly, reduced levels of $\mathrm{Spt} \mathrm{SLIK}_{\mathrm{SLK}}$ and $\mathrm{Spt} \mathrm{F}_{\mathrm{Form} 3}$ were observed in a strain lacking the SAGA component Ubp8, suggesting a regulatory role for Ubp8 in the truncation of Spt7.
\end{abstract}

Conclusion: We conclude that truncation of Spt7 occurs early in the biosynthesis of distinct Spt7 containing complexes rather than being a dynamic process linked to the action of the SAGA complex in transcriptional regulation.

\section{Background}

The multisubunit SAGA (Spt-Ada-Gcn5-Acetyltransferase) complex is a prototype for transcriptional coactivators that interface between DNA binding transcriptional regulators, the chromosomal template and the basal transcriptional machinery [1]. SAGA is a dynamic entity, with components existing in subcomplexes having related but distinct functions [2-6].
The Ada components of SAGA (ADA2, NGG1/ADA3, GCN5/ADA4) were first identified based on their involvement in regulated transcription in Saccharomyces cerevisiae [7-11]. SAGA possesses histone acetyltransferase (HAT) activity mediated by Gcn5 $[2,12]$, which stimulates or represses transcription in a promoter specific fashion [1317]. The structural core of SAGA is composed of a subset of the TBP-associated factors (TAFs) that are also found in 
TFIID $[18,19]$. Spt7, Ada1 and Spt20, members of the TBP-subclass of Spt (Suppressors of Ty insertions) [2,2022] proteins, are located near the core of the complex and are required for its integrity, forming an interface between TAFs and other SAGA-specific components [19]. The additional Spt proteins, Spt3 and Spt8 are involved in direct interactions with TBP [3,22-25]. Tra1, a $437 \mathrm{kDa}$, phosphatidylinositol-3-kinase related protein $[26,27]$ is found at the periphery of the complex and interacts with DNAbinding transcriptional regulators thus conferring promoter specificity to SAGA [28-32]. Through mass spectrometry analysis of purified SAGA complex, other components have been identified [33-36]. One of these proteins, Sus1, is associated with the nuclear pore mRNA export machinery [35] suggesting that SAGA may have a broader role in nuclear processes than previously envisioned.

Two forms of Spt7 have been described. The full-length protein of 1332 amino acid residues is found within the SAGA complex [2]. The second, a C-terminally truncated form likely arising from processing between residues 1125 and 1150 is found in the SLIK (SAGA-like) complex [3-6]. As suggested by the alternate name for this complex, SALSA (SAGA altered, Spt8 absent), SLIK also differs from SAGA in that it lacks Spt8 $[3,4]$. The absence of Spt8 can be attributed to the fact that it interacts with Spt7 in the region deleted in the truncated form $[4,6]$. The truncation of Spt7 and the subsequent loss of Spt8 may be a mechanism to create a complex that acts without effects mediated through TBP; for example, the derepression of the HIS3 promoter under starvation conditions [3,4]. A further difference between SAGA and SLIK is that Rtg2, which is required for the retrograde response pathway in yeast [37], is found specifically in SLIK [5]. Two other Rtg proteins, Rtg1 and Rtg3 are transcription factors required for the expression of retrograde target genes such as CIT2 [38]. Pray-Grant et al. [5] propose that SLIK facilitates transcriptional activation by Rtg1 and Rtg3 and perhaps also at a distinct set of promoters. However, the exact role of SLIK is unclear as the interpretation of transcriptional effects upon disruption of RTG2 is complicated since Rtg2 is required for nuclear import of Rtg1 and Rtg3 [39].

Two models for the relationship between the Spt7-containing complexes can be envisioned. In the first, processing at the C-terminus would occur as part of the biosynthesis of distinct SAGA and SLIK complexes. Alternatively, processing might occur during the normal functioning of SAGA, perhaps to irreversibly signal that a transcriptional event had occurred and/or enabling subsequent activity of the SLIK complex. In this study we performed experiments to differentiate between these models. We show that the conversion of Spt7 from its fulllength SAGA-form $\left(\mathrm{Spt} 7_{\mathrm{SAGA}}\right)$ to its truncated SLIK-form
$\left(S p t 7_{\text {SLIK }}\right)$ and a third C-terminally processed form (Spt7 ${ }_{\text {Form3 } 3}$ ) occurs in the absence of components of the complex including Ada1 and Spt20, which are required for the integrity of the complex. Processing to these forms occurs rapidly after its synthesis and in the absence of fulllength Spt7. Taken together our results suggest that processing of Spt7 occurs in the biosynthesis of distinct Spt7-containing complexes.

\section{Results and discussion \\ Truncated forms of Spt7 occur in the absence of fully functional SAGA complex}

Two forms of Spt7 have been described that differ in their length [3-6]. Full-length Spt7 is 1332 amino acid residues and is found in the SAGA complex. This form, Spt7 SAGA $^{\prime}$ migrates with an apparent molecular mass of approximately $200 \mathrm{kDa}$ on SDS-PAGE. The SLIK complex contains a C-terminal truncation of Spt7 that results in an apparent molecular mass of approximately $180 \mathrm{kDa}$ [4]. Based upon the mobility of this form and the differential function of Spt7 derivatives with C-terminal deletions, Spt $7_{\text {SLIK }}$ is predicted to contain a C-terminal truncation of approximately 200 amino acids [4,6]. To detect these forms of Spt7 we engineered a centromeric plasmid expressing a TAP and Flag-tagged version of Spt7 that could be identified after C-terminal truncation (YCpDedTAP-Flag-SPT7, Figure 1a). We first addressed whether this molecule was functional by determining if it would complement a deletion of $s p t 7$ as assayed by growth on media depleted for inositol. As shown in Figure 1b, a strain lacking SPT7 is unable to grow on media lacking inositol. YCpDed-TAP-Flag-SPT7 allows for near complete restoration of growth.

To determine if the components of the SAGA or SLIK complex influence the truncation of Spt7, we introduced YCpDed-TAP-Flag-SPT7 into yeast strain BY4741 (wild-type) and isogenic strains deleted for GCN5, RTG2, SPT8, UBP8, ADA1 and SPT20. Cells were grown in YPD media and protein extracts examined for Spt7 by Western blotting with anti-Flag antibody (Figure 2a). Two proteins with apparent molecular masses of approximately 220 and 200 $\mathrm{kDa}$ were present in wild-type cells containing YCpDedTAP-Flag-SPT7 but not in control cells (compare lanes 1 and 2). The size of these molecules suggest that they represent the TAP-Flag tagged full-length ( $\left.\mathrm{Spt} 7_{\mathrm{SAGA}}\right)$ and SLIK-forms $\left(\mathrm{Spt} 7_{\text {SLIK }}\right)$ of Spt7. The ratio of SAGA:SLIK forms of Spt7 was 3:1 in the wild-type strain BY4741 (lane 2). This relative amount of $\mathrm{Spt} 7_{\mathrm{SLIK}}$ was not reduced upon disruption of GCN5, RTG2, ADA1, SPT20 or SPT8. Since Spt20 and Ada1 are required for the integrity of the SAGA complex [6], the presence of Spt $7_{\text {SLIK }}$ in these deletion strains indicates that C-terminal processing can occur in the absence of the fully intact and functional complex. (We do note that there was an apparent decrease in the 

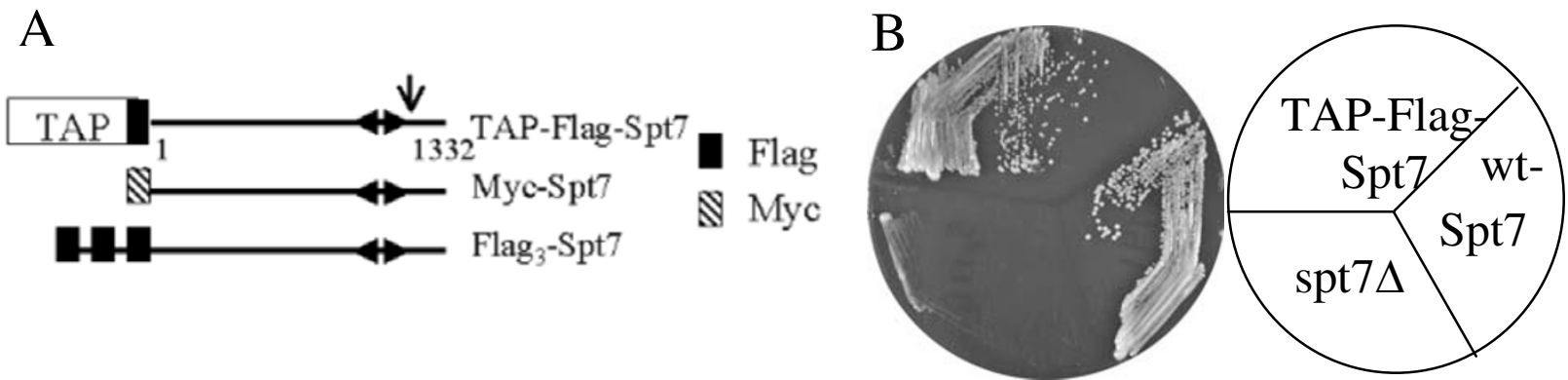

\begin{abstract}
Figure I
Epitope-tagged Spt7 molecules used in this study. A TAP-Flag-Spt7 contains N-terminal TAP and Flag tags fused in frame to the initiator Met of Spt7 (I 332 amino acids) via a triple alanine linker encoded by a Notl site. Myc-Spt7 has a similar constructed Nterminal myc-epitope while Flag ${ }_{3}$-Spt7 contains 3 tandem copies of the Flag epitope. The position of the histone fold (amino acids 979-1045; [43]) is indicated with inverted arrows. An arrow indicates the approximate position of the cleavage site that

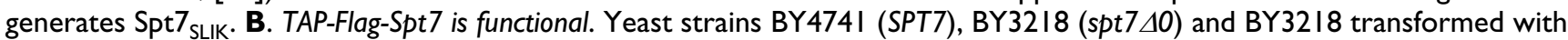
YCPDed-TAP-Flag-SPT7 were grown on a minimal plate depleted of inositol for 3 days at $30^{\circ} \mathrm{C}$.
\end{abstract}

ratio of SAGA:SLIK forms in the spt20 20 strain and speculate that this may be due to differential stability of the forms in this strain background.) In addition, the wildtype level of Spt $7_{\text {SLIK }}$ seen in the spt8 deletion background suggests that the Spt8 interaction with Spt7 does not alter access of the putative processing enzyme(s) to the cleavage site. Furthermore, the lack of a requirement for Rtg2 indicates that the SLIK complex need not fully assemble to allow truncation of Spt7.

Although still apparent, the amount of $\operatorname{Spt} 7_{\text {SLIK }}$ was reduced approximately three-fold in the strain deleted for the ubiquitin protease Ubp 8 (Figure $2 \mathrm{a}$, lane 6 ). We note that the $u b p 8 \Delta 0$ effect was found to vary from approximately two-fold to five-fold between different experiments (not shown). To determine whether the role of Ubp8 was the result of its involvement with SAGA, we examined the Spt7 forms in a strain deleted for Sgf11, a subunit of SAGA required for the association of Ubp8 with components of the complex [40-42]. As shown in Figure 2b, deletion of $s g f 11$ partially reduced the level of Spt7 $7_{\text {SLIK. }}$ This effect was not to the same extent as deletion of Ubp8, perhaps because low levels of Ubp8 remain associated with SAGA in the absence of Sgf11 [40]. Nonetheless, while not eliminating other mechanisms, the result is consistent with a model whereby binding of Ubp8 to SAGA may alter the accessibility of the C-terminus of Spt7 to cleavage. Interestingly, another Flag-antibody reactive band, Spt7 $7_{\text {Form3 }}$, was evident in the sample lanes but not in the control. Since Spt7 $7_{\text {Form3 }}$ was somewhat obscured by a Flag antibody cross-reactive band, we analyzed the Spt7 forms in different strain backgrounds after first purifying TAP-Flag-Spt7 on IgG-agarose (Figure 2c). After purifica- tion a Flag-reactive molecule with an apparent mass approximately $20 \mathrm{kDa}$ less than $\mathrm{Spt} 7_{\text {SLI }}$ (also see Figure $3 b)$ was revealed. The observed difference in mass of this molecule relative to intact 5 pt7 estimates an end-point at approximately amino acid residue 950. As was the case for Spt7 ${ }_{\text {SLIK, }}$ the level of this third form of Spt7 was comparable in each of the deletion strains (gcn5 $\Delta 0$, spt8 $\Delta 0$, $s p t 20 \Delta 0$, ada1 $\Delta 0, r \operatorname{tg} 2 \Delta 0$ ) with the exception of $u b p 8 \Delta 0$ where it was reduced.

\section{C-terminal processing of Spt7 occurs in the absence of its $\mathbf{N}$-terminal amino acid residues}

The finding that Spt7 $7_{\text {SLIK }}$ and Spt $7_{\text {Form3 } 3}$ were formed in the absence of components of SAGA, including Spt20 and Ada1, suggested that processing is not linked directly to the activity of the complex. If processing were part of the functional dynamics of SAGA, that is, occurring as a result of its activities in the regulation of transcription, then one would predict that it would require Spt7 in a functional form. We thus examined whether $\mathrm{N}$-terminal deletion derivatives of Spt7, expressed in BY3218 (spt7 $\Delta 0$ ) would be processed (Figure 3 ). Each molecule was N-terminally TAP and Flag tagged to allow purification and identification of Spt7 forms. The two longest derivatives (residues 580-1332 and 873-1332) contain the elements of the protein required for partial function [6]. By comparison, the shortest derivative (residues 1038-1332) lacks the histone fold, which is required for interaction with other components of the complex [43]. A protein reduced by approximately $20 \mathrm{kDa}$, an estimated mass consistent with a truncation at the $\mathrm{Spt} 7_{\text {SLIK }}$ processing site, was seen for each of the derivatives (denoted as SL). A further truncation, approximately $20 \mathrm{kDa}$ smaller than $\mathrm{Spt} 7_{\text {SLIK }}$ and 

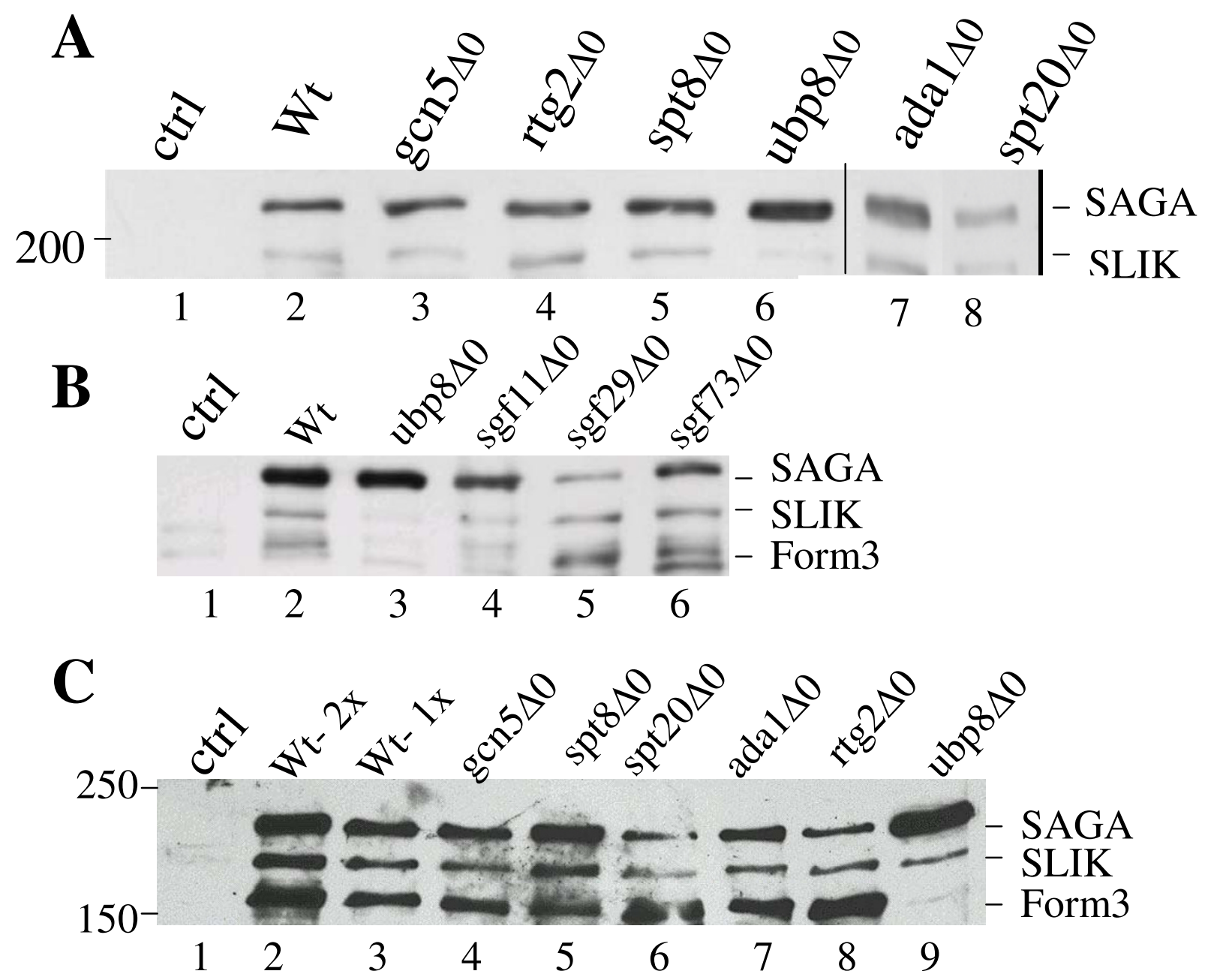

\section{Figure 2}

Processed forms of Spt7 in yeast deletion strains. A. Wild-type (BY474I) or the indicated yeast deletion strains (gcn5 $\Delta 0, r t g 2 \Delta 0$, spt8 $\Delta 0$, ubp8 $\Delta 0$, ada I $\Delta 0$, spt20 $\Delta 0$; lanes 3-8, respectively) were transformed with YCpDed-TAP-Flag-SPT7, with the exception of lane I (ctrl) which was transformed with the control vector YCP-TAP-Flag. Cells were grown to an $A_{600}=1.0-I .5$ in YP containing $2 \%$ glucose and crude cell lysates prepared by glass bead disruption. $50 \mu \mathrm{g}$ of protein was separated by $5 \%$ SDSPAGE and Western blotted with anti-Flag antibody. The mobility of a $200 \mathrm{kDa}$ molecular weight marker is indicated on the left.

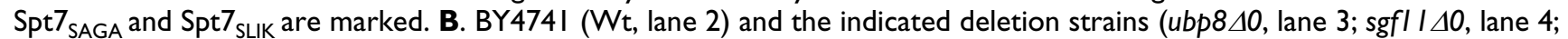
sgf29 $\triangle 0$, lane 5; sgf73 $\Delta 0$, lane 6) containing TAP-Flag-Spt7 were grown as above, crude yeast extracts separated by SDS-PAGE and Western blotted with anti-Flag-antibody. Lane one contains crude extract from the wild-type strain BY474I. Spt7 SAGA,

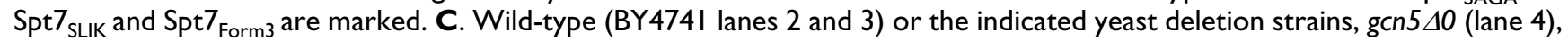
spt8 $\Delta 0$ (lane 5), spt20 $\Delta 0$ (lane 6), adal $\Delta 0$ (lane 7), rtg2 $\Delta 0$ (lane 8), ubp8 $\Delta 0$ (lane 9) containing YCpDed-TAP-Flag-SPT7 were grown in YP broth containing $2 \%$ glucose. Lane I (ctrl) contains BY474I transformed with the control vector YCP-TAP-Flag. TAP-Flag-Spt7 was purified through affinity chromatography on IgG-Agarose and eluted after cleavage with TEV protease. Approximately equal amounts of Spt7 were separated by 5\% SDS-PAGE and Western blotted with anti-Flag antibody. The mobility of 250 and $150 \mathrm{kDa}$ molecular mass markers are indicated on the left. Lane 3 contains one half of the wild-type sample applied in lane 2 to facilitate quantitation. 

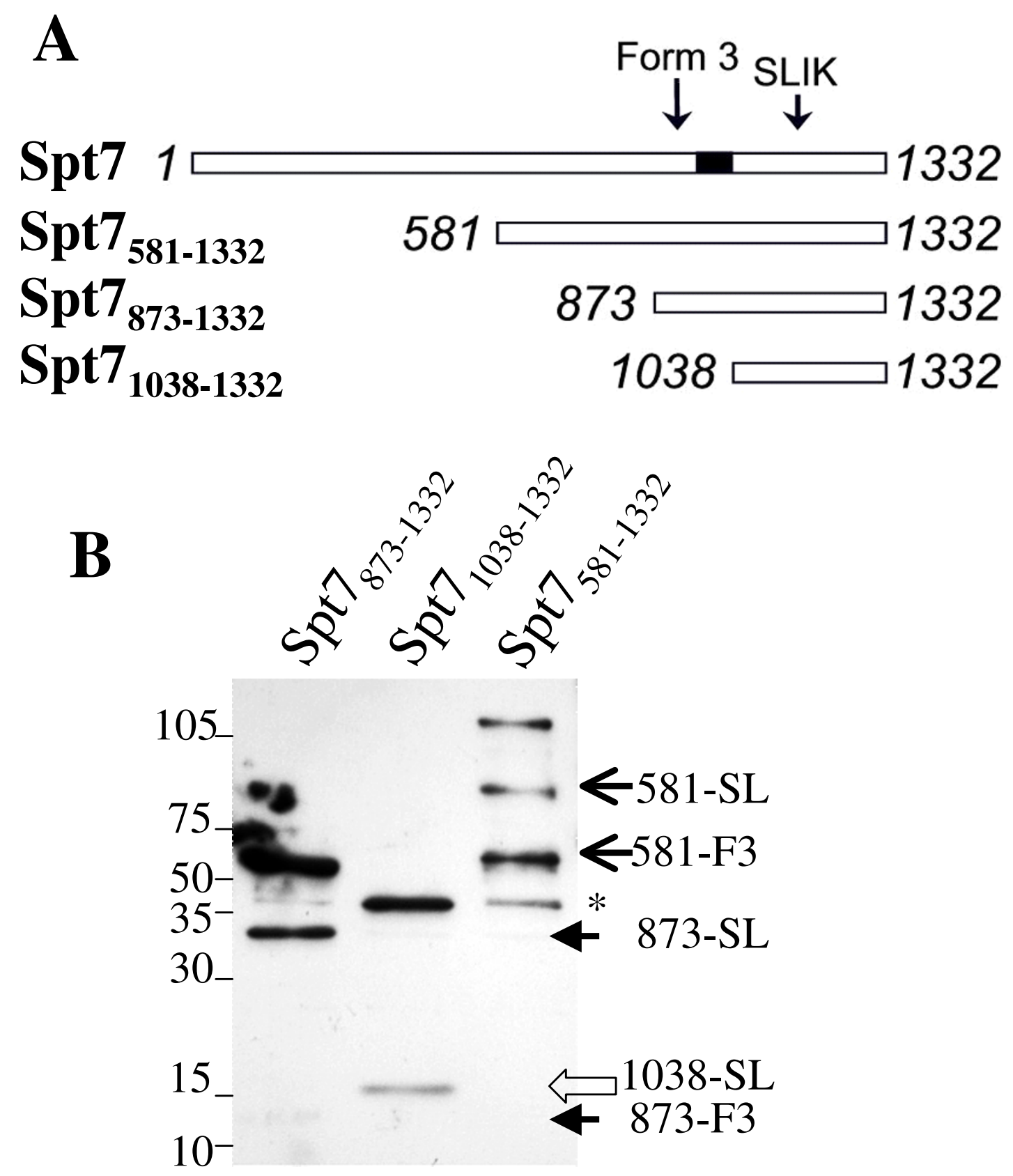

\section{Figure 3}

Formation of truncated forms of Spt7 in N-terminally deleted derivatives. A. N-terminally deleted derivatives of Spt7 were constructed containing amino acids 58I-I 332 (Spt7 58 I-1332), 873-1332 (Spt7 $873-1332$ ) and I038-1332 (Spt7 1038-1332). Note that each molecule is N-terminally TAP and Flag tagged to allow purification then detection of processed fragments. The position of the

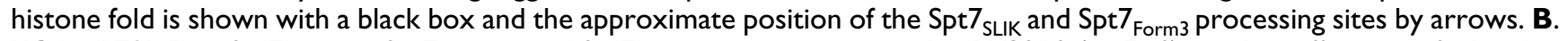
YCpDed-TAP-Flag- Spt7 $581-1332$, Spt7 $_{873-1332}$ and Spt7 ${ }_{1038-1332}$ were expressed in BY32 I8 (spt7 $\Delta 0$ ), tandem affinity purified and Spt7 forms detected by Western blotting with anti-Flag antibody after electrophoresis on an 8-I5\% gradient gel. Mobility of protein standards with the indicated molecular masses $(\mathrm{kDa})$ is indicated on the left. Arrows on the right marked with $58 \mathrm{I}, 873$ and 1038 represent the mobility of truncated TAP-Flag- Spt7 $581-1332$, Spt7 $873-1332$ and Spt7 $7_{1038-1332}$, respectively. $*$ marks an additional cleavage product seen with $\mathrm{Spt}_{58 \mathrm{I}-1332}$. 
potentially corresponding to processing at the $\mathrm{Spt} 7_{\text {Form3 }}$ site (F3), was evident for Spt7 $7_{581-1332}$ and Spt7 $873-1332$ (though at a reduced level). Note that the third-form equivalent was not seen for Spt $7_{1037-1332}$, because its putative cleavage site is removed from this construct. This result suggests that the elements required for processing are intrinsic to the C-terminal end of Spt7 and that the Nterminus of the protein is not required. Furthermore, the appearance of a cleavage product for Spt $7_{1037-1332}$ suggests that processing can take place independently from SAGA and is thus not linked to the action of the complex. For Spt7 ${ }_{581-1332}$, a fourth form was apparent just below Form 3 (marked by ${ }^{*}$ ). We have not characterized this form further and can not exclude that it is a degradation product.

If the forms of Spt7 were created progressively from one another in response to the activity of the complex, one would predict that the longer forms would be chased into shorter forms. We analyzed the appearance and disappearance of the Spt7 forms upon inducing expression of a triple Flag-tagged Spt7 under control of the GAL10 promoter (GAL-Flag ${ }_{3}$-Spt7; see Figure 1). As shown in Figure $4 \mathrm{a}$, cells containing $\mathrm{GAL}$-Flag ${ }_{3}$-Spt7 rapidly induce the three Spt7 forms when shifted from raffinose to galactose containing media but not upon shifting to glucose containing media. Figure $4 \mathrm{~b}$ is a time course of the appearance and disappearance of the Spt7 forms after induction in galactose containing media and subsequent shift to media containing glucose. Expression of the forms continued to increase after promoter shut-off until approximately the 60 minute time point. All three forms increased at approximately the same rate. After $60 \mathrm{~min}$ utes, the amounts of the Spt7 forms began to decay. This was in contrast to total protein, which continued to increase (comparing the Western blot versus the stained gel in Figure 4b). Similar to their appearance, the three forms disappeared at approximately the same rate. The longer forms were not chased into the shorter molecules, suggesting that $\mathrm{Spt} 7_{\mathrm{SLIK}}$ and $\mathrm{Spt} 7_{\mathrm{Form} 3}$ are produced early after the synthesis of Spt7 ${ }_{\text {SAGA }}$ and not sequentially as the result of the action of the complex. Combined with the results above, processing appears inherent to the C-terminus of the molecule and occurs independently from the action of the SAGA complex.

\section{Further characterization of the $160 \mathrm{kDa}$ form of Spt7}

To eliminate the possibility that the appearance of Spt7 ${ }_{\text {Form3 }}$ was related to blotting with Flag antibody or to the TAP-tag, we expressed N-terminally myc-tagged Spt7, separated crude protein extract by SDS-PAGE and blotted with anti-myc antibody (Figure 5a). A band approximately $20 \mathrm{kDa}$ smaller than myc-Spt7 SAGA likely mycSpt7 ${ }_{\text {SLIK }}$ was present in wild-type cells containing YCp88$m y c$-SPT7 but not in control cells (compare lanes 1 and 2) as was the third-form at an apparent mass of $160 \mathrm{kDa}$. To determine if $\mathrm{Spt} 7_{\text {Form3 }}$ was an artifact of the partial TAP purification or expression in cells also containing a wildtype copy of SPT7, we purified TAP-Flag-Spt7 from BY4741 (wild-type) and BY3281 (spt7 $\Delta 0$ ) through both tandem affinity steps, IgG-Agarose and CalmodulinSepharose. As shown in Figure 5b, a 160 kDa, Flagdetected protein was apparent after purification (lanes 2 and 4) and not in a mock purification (lanes 1 and 3) in both strain backgrounds.

To examine if $\mathrm{Spt} 7_{\mathrm{Form} 3}$ is found within complexes, TAPFlag-Spt7 was expressed in BY4741 and a crude protein extract applied to a Superose 6 HR10/30 gel filtration column. The elution profile of the different forms of Spt7 was examined by Western blotting with anti-Flag antibody and the relative amounts of the three forms of Spt7 determined by densitometry (Figure 5c). All three forms of Spt7 eluted in fractions corresponding to a high molecular mass, the largest being $S p t 7_{\text {SAGA}}$ followed by $\mathrm{Spt} 7_{\text {SLIK }}$. Spt7 $7_{\text {Form } 3}$ eluted from the column with an average apparent molecular size slightly less than $S p t 7_{\text {SLIK }}$. To determine if Spt7 ${ }_{\text {Form } 3}$ was associated with components of the SAGA complex, extracts were prepared from strains containing N-terminally Flag-tagged Spt7 and TAP-tagged versions of Gcn5, Ada2, Ubp8, Taf5, Spt3 and Spt8. Complexes containing the TAP-tagged molecules were partially purified and the presence of the different forms of Spt7 analyzed by Western blotting with anti-Flag antibody (Figure $5 \mathrm{~d}$, lanes 3-9). Identification of the forms was established by immunoprecipitation of Flag-Spt7 from crude extracts with anti-Flag antibody (compare lanes 1 and 2). As expected from the interaction of Spt 8 with the C-terminal end of Spt7 $[4,6]$, Spt 8 interacted only with full-length Spt7 (lane 8). The other SAGA components interacted with both $\mathrm{Spt} 7_{\text {SAGA }}$ and $\mathrm{Spt} 7_{\text {SLIK }}$ Spt7 $7_{\text {Form3 }}$ did not COpurify with the SAGA components to the extent of either Spt7 $7_{\text {SAGA }}$ or Spt7 $7_{\text {SLIK }}$.

The function of $S p t 7_{\text {Form3 } 3}$ is unknown. The fact that Spt7 $7_{\text {Form } 3}$ appears as stable as the longer forms is consistent with it having a function(s), likely distinct from components of the SAGA complex. It is interesting to note that Spt7 has been found to associate with Ccl1, Rtf1 and Prp43, and that these interactions are not reciprocated by C-terminally TAP-tagged Spt7 or generally by other components of the SAGA complex (Saccharomyces Genome Database). In addition, we previously observed a possible SAGA-independent form of Spt7 by fractionation of crude extracts on a Mono Q column [27]. We also must consider an alternative model, whereby $\mathrm{Spt} 7_{\mathrm{Form} 3}$ is an intermediate along a pathway of degradation. In this regard, we did observe an apparent increase in $\mathrm{Spt} 7_{\text {Form3 }}$ during TAPpurification. 


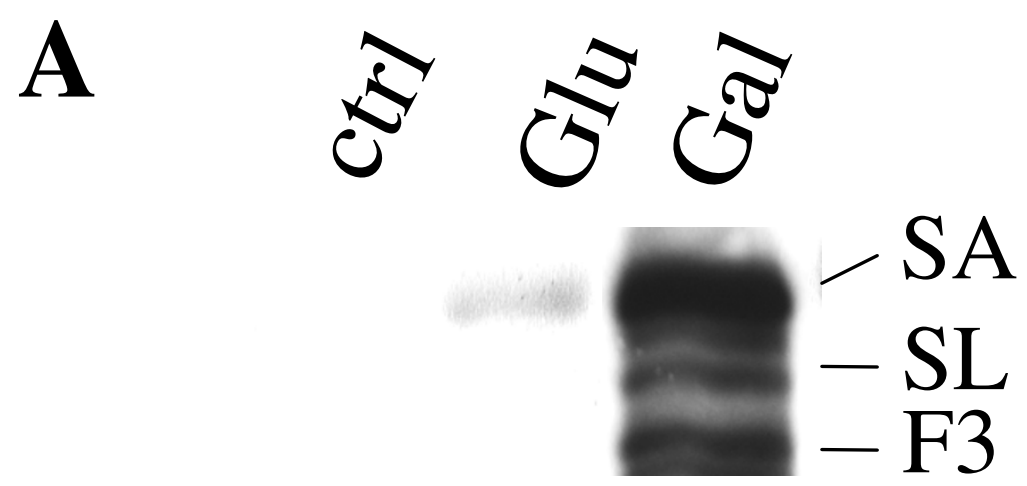

B

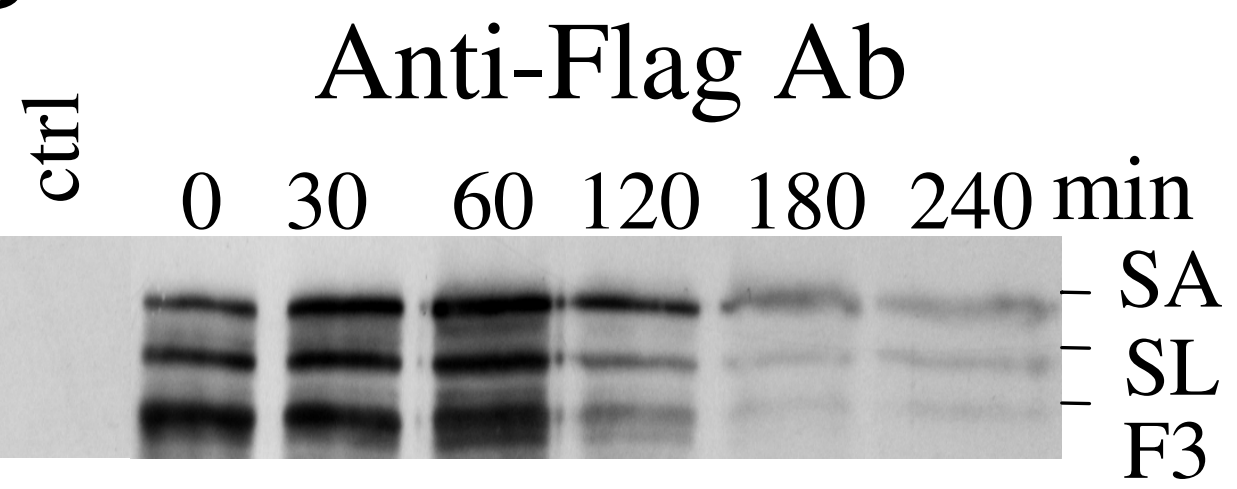

\section{Coomassie Brilliant Blue}

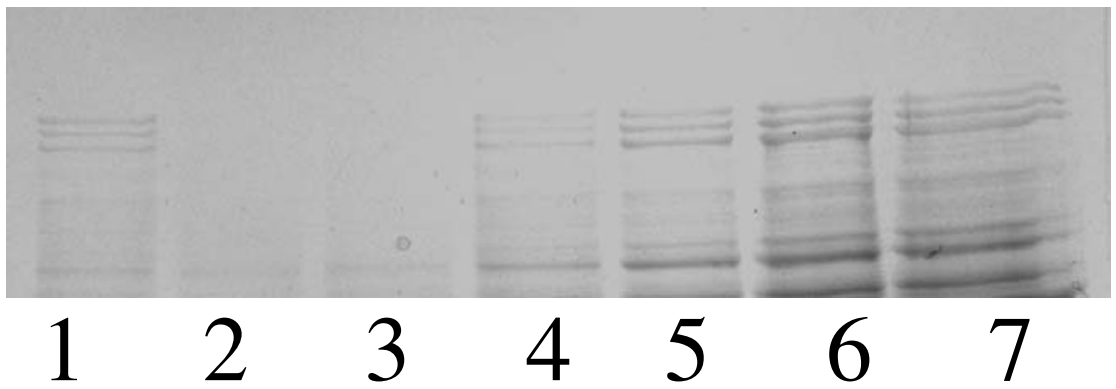

Figure 4

Time course of the induction and decay of Spt7 forms. A. CY I 8 I I containing Ylplac2 I I-GAL-Flag ${ }_{3}$-SPT7 was grown in minimal media containing $2 \%$ raffinose then diluted I:5 into YP media containing $2 \%$ glucose (lane 2) or 2\%galactose (lane 3 ) and grown for 30 minutes. Extracts were prepared by glass bead disruption and $100 \mu \mathrm{g}$ separated by SDS-PAGE (5\%). Flag ${ }_{3}$-Spt7 was detected by Western blotting with anti-Flag antibody. Lane one contains $100 \mu \mathrm{g}$ of protein extract prepared after growth of BY474I in galactose-containing media. B. CYI8I I containing Ylplac2 I I-GAL - Flag 3 -SPT7 was grown in raffinose. Expression of Spt7 was induced by the addition of galactose then inhibited by the addition of YP media containing $2 \%$ glucose. Cells were grown for 90 minutes which was empirically determined as time 0 . Additional equal volume samples were taken at time $0,30,60,120$ and 240 minutes (lanes 2-7). Protein extracts were prepared and equal volumes separated by SDS-Page (5\%). Flag ${ }_{3}-$ Spt7 was detected by Western blotting (top panel) or stained with Coomassie Brilliant Blue (bottom panel). 

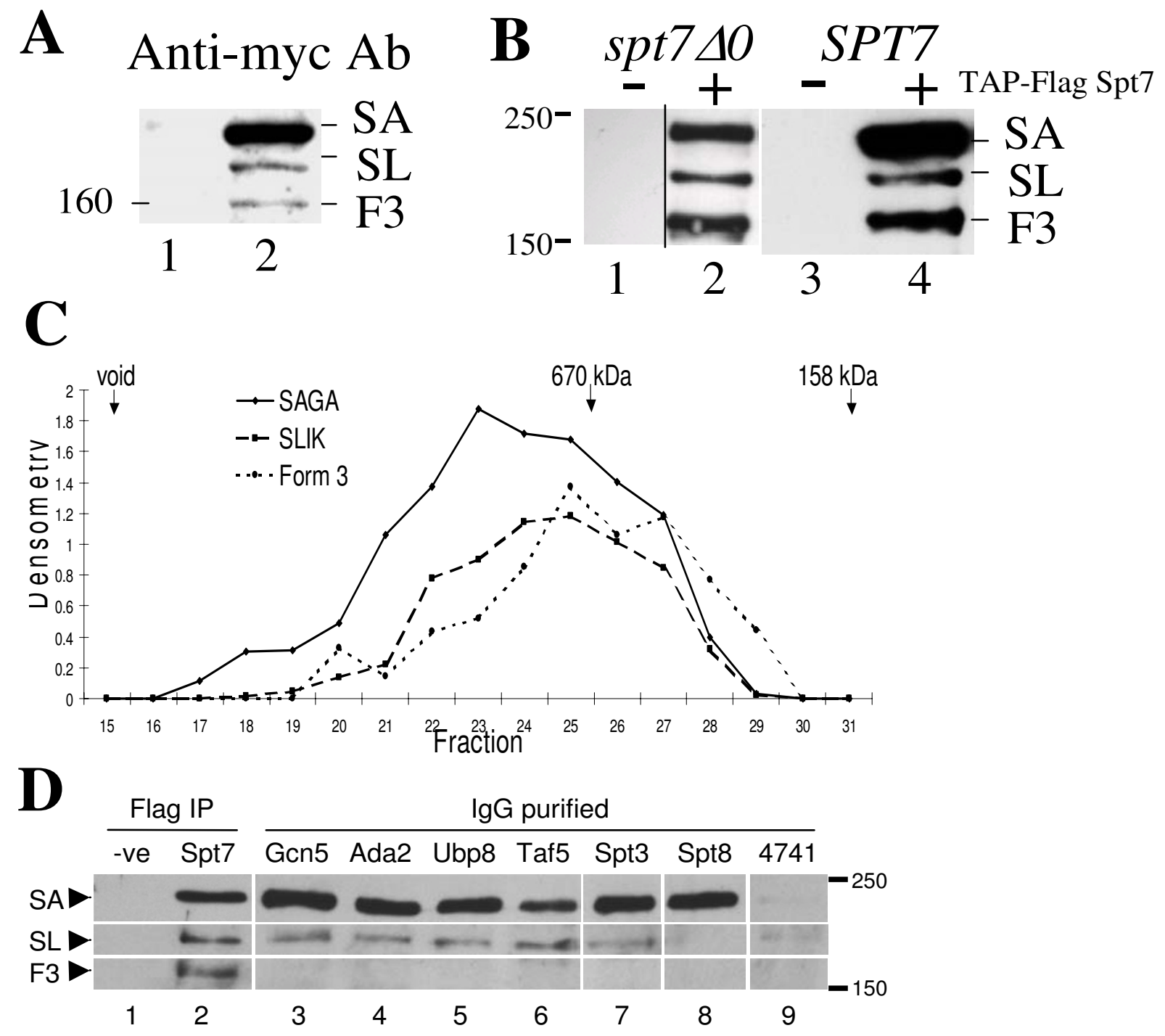

\section{Figure 5}

Characterization of Spt7 Form3. A. YCp88-myc was transformed into BY474I (lane I, ctrl) and YCp88-myc-SPT7 into BY474I (lane 2). Crude protein extracts were prepared and Western blotted with anti-myc antibody. The mobility of a $160 \mathrm{kDa}$ molecular weight marker is indicated. Spt7 Form 3 is marked as F3. B. BY474I (wild-type, right panel) and BY32 I8 (spt7 $\Delta 0$, left panel) were transformed with YCpDed-TAP-Flag (lanes I and 3) or YCpDed-TAP-Flag-SPT7 into (lanes 2 and 4). Extracts were prepared by grinding I litre of cells in liquid nitrogen, and subjected to TAP purification. $20 \mu$ of the peak fractions were blotted with anti-Flag antibody. C. Gel filtration chromatography of Spt7 from crude yeast extracts. $8.5 \mathrm{mg}$ of protein extract was prepared from yeast strain BY474I containing YCpDed-TAP-Flag-SPT7 and applied to a Superose 6 HR I0/30 column (Pharmacia). $500 \mu \mathrm{l}$ fractions were collected, precipitated with 10\% trichloroacetic acid, separated on a 5\% SDS-polyacrylamide gel and Western blotted with anti-Flag antibody. Relative amounts of each of the three forms as determined by densitometry are shown as are the peak fraction for elution of the indicated molecular mass standards. D. Wild-type (474I; lane 9) or strains containing C-terminally TAP-tagged Gcn5, Ada2, Ubp8, Taf5, Spt3 and Spt8, expressing Flag-Spt7 (lanes 3-8) were grown in YP media containing $2 \%$ glucose to an $\mathrm{OD}_{600}=2.0$. Twenty-five milligrams of crude lysate was purified on lgG agarose. Bound protein was separated by $5 \%$ SDS-PAGE and Flag-Spt7 forms detected with anti-Flag antibody. To demonstrate the position of the three Spt7 forms lanes I and 2 are extracts of BY474I transformed with YCpDed-Flag-SPT7 that have been purified on Sepharose 4B (-'ve) or anti-Flag antibody coupled to Sepharose (Spt7) then Western blotted with anti-Flag antibody. The positions of

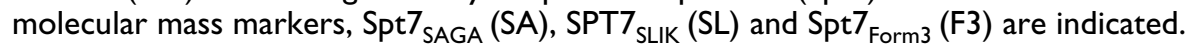




\section{Conclusion}

In this report we show that processing of the C-terminus of Spt7 to the form found in the SLIK complex and to a novel third form does not require a functional SAGA complex. C-terminal truncation occurs in the absence of key components of SAGA and SLIK complexes. Spt20 and Ada1 are necessary for the integrity of a complete SAGA complex with their deletion resulting in severe transcriptional effects [6,22], yet processing occurs in their absence. In addition, since the truncated Spt7 molecules were present in a gcn $5 \Delta 0$ strain, histone acetylation is not required for processing. Also suggesting that processing of Spt7 is independent of the function of SAGA, we found that a truncated derivative of Spt7 that lacks the histone fold is capable of being processed in a strain lacking fulllength Spt7. Finally a time course revealing the appearance and disappearance of the Spt7 forms showed that

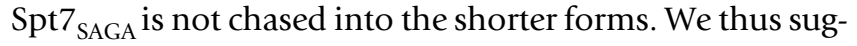
gest that processing of Spt7 is an independent event in the biosynthesis of distinct Spt7 containing complexes rather than being linked to transcriptional regulation by the SAGA complex.

Processing of Spt7 showed partial dependence on the ubiquitin protease Ubp8. The role of Ubp8 is unclear but based on a partial effect upon deletion of Sgf11, it may require the association of Ubp 8 with SAGA. We were intrigued by the possibility that the effect of Ubp8 may be related to our previous observation of the ubiquitylation of Spt7 dependent on the E3-ubiquitin ligase Tom 1 [44]; however, because the relative amounts of the Spt7 forms appear unchanged in a tom $1 \Delta 0$ strain (not shown) we have concluded that these observations are unrelated.

Our study has identified a third form of Spt7 with an apparent molecular mass of $\sim 160 \mathrm{kDa}$. The identification of this form with three different tagged derivatives suggests that it is not an artifact of tagging; however, we can not fully exclude the possibility that N-terminal tagging results in its appearance. Gel-filtration experiments suggest that Spt7 $7_{\text {Form } 3}$ is found within a complex; albeit, distinct from SAGA or SLIK. As Spt7 was N-terminally tagged, the mobility of $\mathrm{Spt} 7_{\text {Form } 3}$ on SDS-PAGE suggests a molecule containing amino acid residues 1 to 950. Determining the size of the released C-terminal fragment would facilitate mapping of the cleavage site; however, we have been unable to identify this molecule using C-terminally TAP-tagged Spt7.

\section{Methods \\ Yeast strains}

The wild-type yeast strains BY4741 (MATa his $\Delta 0$ leu2 $\Delta 0$ met1 $\Delta 0$ ura3 $\Delta 0$ ) and BY4742 (MAT $\alpha$ his $\Delta 0$ leu2 $\Delta 0$ lys $2 \Delta 0$ ura3 $\triangle 0$ ) and the consortium constructed isogenic knock-

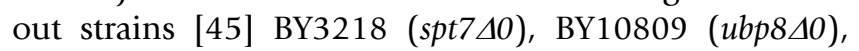

BY17285 (gcn5 40$),$ BY14619 (rtg2 40$),$ BY12666 (spt8 $\Delta 0)$, BY14433 (sgf73 40$), \quad$ BY13418 (sgf29 40$), \quad$ BY2781 (sgf11 $\Delta 0)$, BY1038 (ada1 $\Delta 0)$ and BY17390 (spt20 20$)$, and strains containing C-terminally TAP-tagged SAGA components were purchased from Open Biosystems or Research Genetics. CY1811 is a derivative of BY4741 that contains a YIplac211-GAL-Flag 3 -SPT7 integrated at the endogenous locus.

\section{DNA constructs}

YCpDed-TAP is a derivative of the LEU2 containing centromeric plasmid YCplac111 [46] that contains a DED1 promoter [9] driving expression of a TAP epitope. The DED1 promoter was synthesized by PCR using oligonucleotides 4149-1 and 4149-2 (see Table 1) and cloned as a PstIBamHI fragment into YCplac111. The TAP epitope was subsequently cloned as a BamHI to SstI fragment into this molecule after its PCR using oligonucleotides 4149-4 and 4168-1 and pFA6a as the template (kindly provided by Kathy Gould). The coding sequence for the Flag-epitope was cloned into this molecule at the engineered NotI site using oligonucleotides 4213-1 and 4213-2 to give YCpDed-TAP-Flag. Epitope-tagged Spt7 was constructed through PCR amplification of two tandem parts of the 3999 base pair gene using oligonucleotides 4051-1 and 4051-2 for the 5'-segment and 4009-1 and 4009-2 for the 3 '-segment, respectively. The two segments were ligated using the common internal SalI restriction site and cloned into YCpDed-TAP-Flag as a NotI-Sst fragment to generate YCpDed-TAP-Flag-SPT7. A molecule expressing Myctagged Spt7 was constructed by cloning a NotI-EcoRI fragment from YCpDed-Tap-Flag-SPT7 into the URA3 centromeric plasmid YCp88-myc [9] to generate YCp88-mycSPT7. Single Flag-tagged Spt7 similarly contains a MetTyr-Lys-Asp $\mathrm{P}_{4}$-Lys coding sequence inserted directly before the NotI site.

TAP-tagged derivatives of Spt7 with 752, 460 and 295 Cterminal amino acids were constructed by PCR using oligonucleotides 4009-1, 4536-1 and 4536-2 as 5' primer, and 4009-2 as 3 ' primer. Each was cloned into YCpDedTAP-Flag as a NotI-EcoRI fragment to generate YCpDedTAP-Flag-SPT7 ${ }_{580-1332}, \quad$ YCpDed-TAP-Flag-SPT7 $872-1332$ and YCpDed-TAP-Flag-SPT7 ${ }_{1038-1332}$.

The parent construct for plasmids expressing $\mathrm{Flag}_{3}-\mathrm{Spt} 7$ is pCB1450. This molecule contains a N-terminal Flag epitope (engineered with oligonucleotides 2821-1 and 2821-2) flanked upstream by the PstI site of the pUC polylinker and downstream by a NotI site. Genes to be expressed can be inserted as NotI-(SacI)EcoRI fragments. The polylinker HindIII site was deleted allowing insertion of promoter fragments as PstI-HindIII fragments. The GAL10 promoter was synthesized by PCR using oligonucleotides 2764-1 and 2764-2 and inserted into pCB1450. 
Table I: Oligonucleotides used in this study

\begin{tabular}{lll}
\hline Oligo\# & Sequence (5'-3') & Construct(s) \\
\hline $4009-1$ & GCGGCCGCTGGAAGAAAAGGATTGAATATGG & 3' fragment of SPT7 \\
$4009-2$ & GAATTCTATTCAACTATTTAGCGCGCTC & 5'fragment of SPT7 \\
$4051-1$ & GCGGCCGCAATGACTGAAAGAATACCAATAAAG & \\
$5051-2$ & CCAAATCGTCTCTATCGTCATCC & 5' truncations of SPT7 \\
$4536-1$ & GATGCGGCCGCGATGGAAGACGCTTCCGTG & N-terminal Flag epitope \\
$4536-2$ & GATCGGCCGCCGGTATCAACAGGCCAGAC & TAP-tag \\
$4213-1$ & GGCCGACTACAAGGACGACGATGACAAGGC & DEDI promoter \\
$4149-4$ & GGCCGCCTTGTCATCGTCGTCCTTGTAGTC & GALI0 promoter \\
$4168-1$ & GAGCTCGCGGCCGCATAATCAAGTGCCCCGGAG & Met-Flag tag \\
$4356-1$ & GATGCGGCCGCGATGGAAGACGCTTCGTG & \\
$2764-1$ & GATGCGGCCGCCGGTATCAACAGGCCAGAC & \\
$2764-2$ & AACTGCAGTAATACGCTTAACTGCTC & \\
$2821-1$ & CCCAAGCTTGACGTTAAAGTATAGAGGT & \\
\hline
\end{tabular}

SPT7 from YCpDed-TAP-Flag-SPT7 was inserted as a NotIEcoRI fragment and two additional Flag epitopes were inserted at the NotI site using oligonucleotides 4213-1 and 4213-2. For integration into yeast the GAL-Flag ${ }_{3}-S P T 7$ module was inserted into YIplac211 [46]. Integration into the endogenous locus was possible after digestion with SalI.

\section{TAP purification}

Tandem affinity purification (TAP) was carried out as described [47] with minor modifications. Yeast cells were grown in YPD to an $\mathrm{A}_{600}=1.5$ and lysed by grinding in liquid nitrogen [48]. All further steps were performed at $4{ }^{\circ} \mathrm{C}$. Per liter of starting culture, cell extracts were suspended in 5 ml of IPP150 (10 mM Tris-HCl (pH 8.0), $150 \mathrm{mM}$ $\mathrm{NaCl}, 0.1 \% \mathrm{NP}-40$ ) with protease inhibitors (1 $\mathrm{mM}$ PMSF, $0.1 \mathrm{mM}$ benzamidine hydrochloride, $2 \mu \mathrm{g} / \mathrm{ml}$ pepstatin A, $2 \mu \mathrm{g} / \mathrm{ml}$ leupeptin and $0.1 \mathrm{mg} / \mathrm{ml}$ trypsin inhibitor). The extract was cleared by centrifugation at 40,000 g for $1 \mathrm{~h}$ and incubated with $400 \mu \mathrm{l}$ of IgG-Agarose (SigmaAldrich Canada Ltd) suspension for $2 \mathrm{~h}$. After washing with $30 \mathrm{ml}$ of IPP150 and $10 \mathrm{ml}$ of TEV cleavage buffer (10 mM Tris-HCl (pH 8.0), $150 \mathrm{mM} \mathrm{NaCl}, 0.5 \mathrm{mM}$ EDTA, $1 \mathrm{mM}$ dithiothreitol, $0.1 \%$ NP-40), IgG beads were suspended in $1 \mathrm{ml}$ of TEV cleavage buffer and incubated with $\sim 100 \mathrm{U}$ TEV protease for $2 \mathrm{~h} .3 \mu \mathrm{l}$ of $1 \mathrm{M} \mathrm{CaCl}_{2}$ was added to the TEV-cleaved eluent which was then diluted with 3 $\mathrm{ml}$ of calmodulin binding buffer $(10 \mathrm{mM}$ Tris- $\mathrm{HCl}(\mathrm{pH}$ 8.0), $150 \mathrm{mM} \mathrm{NaCl}, 1 \mathrm{mM}$ magnesium acetate, $1 \mathrm{mM}$ imidazole, $2 \mathrm{mM} \mathrm{CaCl}_{2}, 1 \mathrm{mM}$ beta-mercaptoethanol, $0.1 \%$ NP-40). For the second step of purification the protein was applied to $400 \mu \mathrm{l}$ of Calmodulin-Sepharose (Stratagene Inc) and incubated for $2 \mathrm{~h}$. After the calmodulin beads were washed with $30 \mathrm{ml}$ of calmodulin binding buffer, bound protein was eluted with calmodulin elution buffer (10 mM Tris-HCl (pH 8.0), $150 \mathrm{mM} \mathrm{NaCl}, 1 \mathrm{mM}$ magnesium acetate, $1 \mathrm{mM}$ imidazole, $20 \mathrm{mM}$ EGTA, 1 $\mathrm{mM}$ beta-mercaptoethanol, $0.1 \% \mathrm{NP}-40)$, in $200 \mu \mathrm{lfac}-$ tions. $20 \mu \mathrm{l}$ of the peak fractions were separated by $5 \%$ SDS-PAGE and subjected to Western blotting.

\section{Western blotting}

Yeast extracts were prepared by glass bead disruption [9] or grinding in liquid nitrogen [48]. Protein was separated by SDS polyacrylamide gel electrophoresis, transferred to PVDF membranes (Roche Applied Science) using a wet transfer system (Bio-Rad) in $48 \mathrm{mM}$ Tris, $40 \mathrm{mM}$ glycine, $0.0375 \%$ (6.5 mM) SDS and 20\% methanol for $1 \mathrm{~h}$ at 100 $\mathrm{V}$ and detected using a $20 \%$ solution of Immobilon Western (Millipore Corp). Anti-Flag antibodies (M2, SigmaAldrich Canada Ltd) were used at a ratio of 1:4000; antimyc antibody (Myc1-9E10 cell line) was used at a ratio of 1:2000. Densitometric scanning of films was performed using AlphaImager 3400 software (Alpha Innotech, Inc). Serial dilutions of samples were analyzed to provide standard curves for suitable film exposure.

\section{Time course of the induction and decay of Spt7}

A $10 \mathrm{ml}$ culture of CY1811 was grown to an $\mathrm{A}_{600} \sim 3.0$ in minimal media containing $0.6 \%$ casamino acids (Difco) and $2 \%$ raffinose. The culture was diluted with $10 \mathrm{ml}$ of prewarmed media containing $2 \%$ galactose and grown for 30 minutes at $30^{\circ} \mathrm{C} .80 \mathrm{ml}$ of YP media containing $2 \%$ glucose was added and the cells grown for 90 minutes. This became time 0 , and a $15 \mathrm{ml}$ sample was taken. Cells were pelleted by centrifugation, washed in ice-cold water and frozen at $-80^{\circ} \mathrm{C}$. Additional samples were taken after $30,60,120$ and 240 minutes. Yeast extracts were prepared by glass bead disruption in $20 \mathrm{mM}$ Hepes- $\mathrm{NaOH}(\mathrm{pH}$ 8.0), $240 \mathrm{mM} \mathrm{NaCl}$ containing protease inhibitors. Equal volumes were separated by SDS-PAGE (5\%) and Western blotted with anti-Flag antibody. 


\section{Gel-filtration chromatography}

Approximately $8.5 \mathrm{mg}$ of whole cell extract from BY4741 containing YCpDed-TAP-Flag-SPT7 was prepared in 40 $\mathrm{mM}$ Tris- $\mathrm{HCl}$ (pH 7.7), $300 \mathrm{mM} \mathrm{NaCl}, 0.1 \%$ Nonidet P40 and $10 \%$ glycerol, and subsequently applied to a Superose 6 HR10/30 column (Pharmacia Inc) at a flow rate of $0.3 \mathrm{ml} / \mathrm{min}$. Protein from $250 \mu \mathrm{l}$ aliquots of $500-\mu \mathrm{l}$ selected fractions were precipitated with 10\% trichloroacetic acid, acetone washed, resuspended in SDS loading buffer and separated on a 5\% SDS-polyacrylamide gel.

\section{Authors' contributions}

SH carried out the analysis of Spt7 in yeast deletion strains, copurifications and mapping studies. GL performed analyses with Spt7 deletion constructs and biochemical fractionation of Spt7. AM performed functional analyses of Spt7 alleles. JG carried out the time course analysis of Spt7 synthesis and degradation. CB directed the experiments and wrote the manuscript.

\section{Acknowledgements}

We would like to thank Amy Tong and Drs. Brenda Andrews, Charlie Boone and Kathleen Gould for providing reagents as well as David Canton, David Litchfield, Meagan Davey, David Edgell, Kerri Kobryn and David Haniford for their discussions on this manuscript. This work was supported by a Canadian Institutes of Health Research operating grant to $\mathrm{CB}$. $\mathrm{SH}$ is supported by a NSERC studentship, GL and AM by Western Graduate Research Scholarships.

\section{References}

I. Sterner DE, Berger SL: Acetylation of histones and transcription-related factors. Microbiol Mol Biol Rev 2000, 64:435-459.

2. Grant PA, Duggan L, Côté J, Roberts SM, Brownell JE, Candau R, Ohba R, Owen-Hughes T, Allis CD, Winston F, Berger SL, Workman $\mathrm{JL}$ : Yeast Gcn5 functions in two multisubunit complexes to acetylate nucleosomal histones: characterization of an Ada complex and the SAGA (Spt/Ada) complex. Genes Dev 1997, II:1640-1650.

3. Belotserkovskaya R, Sterner DE, Deng M, Sayre MH, Lieberman PM, Berger SL: Inhibition of TATA-binding protein function by SAGA subunits Spt3 and Spt8 at Gen4-activated promoters. Mol Cell Biol 2000, 20:634-647.

4. Sterner DE, Belotesrkovskaya R, Berger SL: SALSA, a variant of yeast SAGA, contains truncated Spt7, which correlates with activated transcription. Proc Natl Acad Sci USA 2002, 99(18): I I622-II627.

5. Pray-Grant MG, Schieltz D, McMahon SJ, Wood JM, Kennedy EL, Cook RG, Workman JL, Yates JR 3rd, Grant PA: The novel SLIK histone acetylatransferase complex functions in the yeast retrograde response pathway. Mol Cell Biol 2002, 22:8774-8786.

6. Wu PY, Winston F: Analysis of Spt7 function in the Saccharomyces cerevisiae SAGA coactivator complex. Mol Cell Biol 2002, 22:5367-5379.

7. Berger SL, Pina B, Silverman N, Marcus GA, Agapite J, Regier JL, Triezenberg SJ, Guarente L: Genetic isolation of ADA2: a potential transcriptional adaptor required for function of certain acidic activation domains. Cell 1992, 70:251-265.

8. Georgakopoulos T, Thireos G: Two distinct yeast transcriptional activators require the function of the GCN5 protein to promote normal levels of transcription. EMBO J 1992, II:4|45-4I52.

9. Brandl CJ, Furlanetto AM, Martens JA, Hamilton KS: Characterization of NGGI, a novel yeast gene required for glucose repression of GAL4p-regulated transcription. EMBO J 1993, I 2:5255-5265.
10. Pina B, Berger S, Marcus GA, Silverman N, Agapite J, Guarente L: ADA3: a gene, identified by resistance to GAL4-VP I6, with properties similar to and different from those of ADA2. Mol Cell Biol 1993, I 3:598I-5989.

II. Marcus GA, Silverman N, Berger SL, Horiuchi J, Guarente L: Functional similarity of physical association between GCN5 and ADA2: putative transcriptional adaptors. EMBO J 1994, 13:4807-48|5.

12. Brownell JE, Zhou J, Ranalli T, Kobayashi R, Edmondson DG, Roth SY, Allis CD: Tetrahymena histone acetyltransferase A: a transcriptional co-activator linking gene expression to histone acetylation. Cell 1996, 84:843-85|.

13. Kuo MH, Zhou J, Jambeck P, Churchill ME, Allis CD: Histone acetyltransferase activity of yeast $G \mathrm{cn} 5 p$ is required for the activation of target genes in vivo. Genes Dev 1998, 12:627-639.

14. Utley RT, Ikeda K, Grant PA, Côté J, Steger DJ, Eberharter A, John S, Workman JL: Transcriptional activators direct histone acetyltransferase complexes to nucleosomes. Nature 1998, 394:498-502.

15. Wang L, Liu L, Berger SL: Critical residues for histone acetylation by GCN5, functioning in Ada and SAGA complexes, are also required for transcriptional function in vivo. Genes Dev 1998, I 2(5):640-653.

16. Ricci AR, Genereaux J, Brandl CJ: Components of the SAGA histone acetylatransferase complex are required for repressed transcription of ARGI in rich medium. Mol Cell Biol 2002, 22:4033-4042.

17. Barbaric S, Walker J, Schmid A, Svejstrup JQ, Horz W: Increasing the rate of chromatin remodeling and gene activation - a novel role for the histone. EMBO J 200I, 20:4944-495I.

18. Grant PA, Schieltz D, Pray-Grant MG, Steger DJ, Reese JC, Yates JR 3rd, Workman JL: A subset of TAFIls are integral components of the SAGA complex required for nucleosome acetylation and transcriptional stimulation. Cell 1998, 94:45-53.

19. Wu PY, Ruhlmann C, Winston F, Schultz P: Molecular architecture of the S. cerevisiae SAGA complex. Mol Cell 2004, 15:199-208.

20. Horiuchi J, Silverman N, Pina B, Marcus GA, Guarente L: ADAI, a novel component of the ADA/GCN5 complex has broader effects than GCN5, ADA2, or ADA3. Mol Cell Biol 1997, 17:3220-3228.

21. Roberts SM, Winston F: Essential functional interactions of SAGA, a Saccharomyces cerevisiae complex of Spt, Ada, and Gcn 5 proteins, with the Snf/Swi and Srb/mediator complexes. Genetics 1997, 147:45 I-465.

22. Sterner DE, Grant PA, Roberts SM, Duggan LJ, Belotesrkovskaya R, Pacella LA, Winston F, Workman JL, Berger SL: Functional organization of the yeast SAGA complex: distinct components involved in structural integrity, nucleosome acetylation, and TATA-Binding protein interaction. Mol Cell Biol I999, 19:86-98.

23. Eisenmann DM, Arndt KM, Ricupero SL, Rodney JW, Winston F: SPT3 interacts with TFIID to allow normal transcription in Saccharomyces cerevisiae. Genes Dev 1992, 6:1319-1331.

24. Eisenmann DM, Chapon C, Roberts SM, Dollard C, Winston F: The Saccharomyces cerevisiae SPT8 gene encodes a very acidic protein that is functionally related to SPT3 and TATA-binding protein. Genetics 1994, I 37:647-657.

25. Dudley AM, Rougeulle C, Winston F: The Spt components of SAGA facilitate TBP binding to a promoter at a post-activator-binding step in vivo. Genes Dev 1999, 13:2940-2945.

26. Grant PA, Schieltz D, Pray-Grant MG, Yates JR 3rd, Workman JL: The ATM-related cofactor Tral is a component of the purified SAGA complex. Mol Cell 1998, 2:863-867.

27. Saleh A, Schieltz D, Ting N, McMahon SB, Litchfield DW, Yates JR 3rd, Lees-Miller SP, Cole MD, Brandl CJ: Tral is a component of the yeast Ada-Spt transcriptional regulatory complexes. J Biol Chem 1998, 273:26559-26565.

28. Brown CE, Howe L, Sousa K, Alley SC, Carrozza MJ, Tan S, Workman J: Recruitment of HAT complexes by direct activator interactions with the ATM-related Tral subunit. Science 200I, 292:2333-2337.

29. Kulesza CA, van Buskirk HA, Cole MD, Reese JC, Smith MM, Engel DA: Adenovirus EIA requires the yeast SAGA histone acetyltransferase complex and associates with SAGA components Gcn5 and Tral. Oncogene 2002, 2 I: | | | I I-I 422. 
30. Bhaumik SR, Raha T, Aiello DP, Green MR: In vivo target of a transcriptional activator revealed by fluorescence resonance energy transfer. Genes Dev 2004, I 8:333-343.

3I. Fishburn J, Mohibullah N, Hahn S: Function of a eukaryotic transcription activator during the transcription cycle. Mol Cell 2005, I 8:369-378.

32. Reeves WM, Hahn S: Targets of the Gal4 Transcription Activator in Functional Transcription Complexes. Mol Cell Biol 2005, 25:9092-9102

33. Sanders SL, Jennings J, Canutescu A, Link AJ, Weil PA: Proteomics of the eukaryotic transcription machinery: identification of proteins associated with components of yeast TFIID by multidimensional mass spectrometry. Mol Cell Biol 2002, 22:4723-4738.

34. Powell DA, Weaver CM, Jennings JL, McAfee KJ, He Y, Weil PA, Link AJ: Cluster analysis of mass spectrometry data reveals a novel component of SAGA. Mol Cell Biol 2004, 24:7249-7259.

35. Rodirguez-Navarro S, Fischer T, Luo MJ, Antunez O, Brettschneider S, Lechner J, Perez-Ortin JE, Reed R, Hurt E: Sus I, a functional component of the SAGA histone acetylase complex and the nuclear pore-associated mRNA export machinery. Cell 2004, I | 6:75-86.

36. Pray-Grant MG, Daniel JA, Schieltz D, Yates JR 3rd, Grant PA: Chd I chromodomain links histone $\mathrm{H3}$ methylation with SAGAand SLIK-dependent acetylation. Nature 2005, 433:434-438.

37. Liu Z, Butow RA: A transcriptional switch in the expression of yeast tricarboxylic acid cycle genes in response to a reduction or loss of respiratory function. Mol Cell Biol 1999, 1 9:6720-6728.

38. Jia Y, Rothermel B, Thornton J, Butow RA: A basic helix-loophelix-leucine zipper transcription complex in yeast functions in a signaling pathway from mitochondria to the nucleus. Mol Cell Biol 1997, I7: I I I0-I I I7.

39. Sekito T, Thornton J, Butow RA: Mitochondria-to-nuclear signaling is regulated by the subcellular localization of the transcription factors Rtglp and Rtg3p. Mol Biol Cell 2000, | |:2|03-2 | |5

40. Ingvarsdottir K, Krogan NJ, Emre NC, Wyce A, Thompson NJ, Emili A, Hughes TR, Greenblatt JF, Berger SL: H2B Ubiquitin Protease Ubp8 and Sgfl I constitute a discrete functional module within the Saccharomyces cerevisiae SAGA complex. Mol Cell Biol 2005, 25: I 162-II72.

4I. Lee KK, Florens L, Swanson SK, Washburn MP, Workman JL: The deubiquitylation activity of Ubp8 is dependent upon Sgf I I and its association with the SAGA complex. Mol Cell Biol 2005, 25: II73-II82.

42. Shukla A, Stanojevic N, Duan Z, Sen PT, Bhaumik SR: Ubp8p, a histone deubiquitinase whose association with SAGA is mediated by Sgf I Ip, differentially regulates lysine 4 methylation of histone $\mathrm{H} 3$ in vivo. Mol Cell Biol 2006, 26:3339-3352.

43. Gangloff YG, Sanders SL, Romier C, Kirschner D, Weil PA, Tora L Davidson I: Histone folds mediate selective heterodimerization of yeast TAF(II) 25 with TFIID components yTAF(II)47 and yTAF(II)65 and with SAGA component ySPT7. Mol Cell Biol 200I, 2 I: I84I-1853.

44. Saleh A, Collart M, Martens JA, Genereaux J, Allard S, Côté J, Brandl $C)$ : Tomlp, a yeast hect-domain protein which mediates transcriptional regulation through the yeast ADA/SAGA coactivator complexes. I Mol Biol 1998, 282:933-946.

45. Winzeler EA, Shoemaker DD, Astromoff A, Liang H, Anderson K, Andre B, Bangham R, Benito R, Boeke JD, Bussey H, Chu AM, Connelly C, Davis K, Dietrich F, Dow SW, El Bakkoury M, Foury F, Friend $\mathrm{SH}$, Gentalen E, Giaever G, Hegemann JH, Jones T, Laub M, Liao H, Davis RW: Functional characterization of the $S$. cerevisiae genome by gene deletion and parallel analysis. Science 1999, 285:901-906.

46. Gietz RD, Sugino A: New yeast $E$. coli shuttle vectors constructed with in vitro mutagenized yeast genes lacking sixbase pair restriction sites. Gene 1988, 74(2):527-534.

47. Rigaut G, Shevchenko A, Rutz B, Wilm M, Mann M, Séraphin B: A generic protein purification method for protein complex characterization and proteome exploration. Nat Biotechnol 1999, 17:1030-1032

48. Saleh A, Lang $\mathrm{V}$, Cook $\mathrm{R}$, Brand $\mathrm{C}$ ): Identification of native complexes containing the yeast coactivator/repressor proteins NGG I/ADA3 and ADA2. J Biol Chem 1997, 272:557I-5578.
Publish with Biomed Central and every scientist can read your work free of charge

"BioMed Central will be the most significant development for disseminating the results of biomedical research in our lifetime. "

Sir Paul Nurse, Cancer Research UK

Your research papers will be:

- available free of charge to the entire biomedical community

- peer reviewed and published immediately upon acceptance

- cited in PubMed and archived on PubMed Central

- yours - you keep the copyright 